\title{
Task Values, Cost, and Choice Decisions in College Physical Education
}

\author{
Ang Chen \\ University of North Carolina at Greensboro \\ Xinlan Liu \\ Southeast University-Nanjing
}

\begin{abstract}
The expectancy-value motivation theory postulates that motivation can be achieved when perceived values in an activity override perceived cost of the activity derived from the effort of achieving. This study was designed to examine types of perceived cost in physical education and the extent to which the cost might affect motivation. Data about attainment, intrinsic, and utility values in physical education were collected using surveys from college students $(n=368)$ in China. Perceived cost was investigated through open-ended written responses and interviews. Disappointment about the curriculum emerged as a major cost to motivation and lack of student autonomy was identified as a direct demotivating factor. Despite the cost, most of the students $(92 \%)$ indicated they would, if given a choice, elect to continue physical education for health benefits and broader motivational impact in life, suggesting that strong positive values of physical activity might override the impact of cost. The findings suggest the importance of emphasizing positive values of physical activity in physical education.
\end{abstract}

Keywords: motivation, college physical education, China

An important goal of physical education is to develop habitual physical activity behaviors to maintain health. In other words, it is expected that students, having received physical education, will be able to motivate themselves to engage in physical activities on their own. This motivated behavior is characterized by voluntary choices, persistent effort, and measurable achievement or improvement. It is the responsibility of school physical education, presumably, to help students at various school levels to develop and sustain the ability to make sound choices, put forth enough effort, and strive to achieve the goal.

A population that has not received much attention in research on physical activity is college students (Keating, Guan, Piñero, \& Bridges, 2005). In the United States., the number of four-year colleges and universities that require

Chen is with the Department of Exercise and Sport Science, University of North Carolina-Greensboro, Greensboro, NC, and Liu is with the Department of Physical Education, Southeast University, Nanjing, China. 
physical education decreased from 90\% in 1959 (Fornia, 1959) to 60\% in 1982 (Trimble \& Hensley, 1984), then increased to 65\% in 1988 (Trimble \& Hensley, 1990), and declined again to $63 \%$ in 1998 (Hensley, 2000). For those with more than 10,000 students enrolled, only $30 \%$ required physical education for graduation (Hensley, 2000). Despite the decline, research findings (Adam \& Brynteson, 1992), though very limited, suggest that required college physical education did contribute to a positive attitude and knowledge about physical activity. For example, a survey study showed that college alumni who took required physical education valued physical activity more and participated in physical activity more often than those who did not have required courses (Adam \& Brynteson, 1992). It is not clear from the study, however, what specific values were appreciated by the former students in terms of importance, intrinsic interest, and usefulness of physical education in relation to their motivation to continue physical activity. It is the purpose of this study to apply the expectancy-value theoretical framework to examine college students' expectancy beliefs for success and perceived values and cost in physical education as related to their motivation for physical education and physical activity.

\section{Expectancy Beliefs and Task Values}

Research has shown that achievement motivation often relies on two primary sources: competence-based expectations for success and perceived values of tasks. According to Wigfield and Eccles (1992), the two constructs actually cut across almost all cognitive theories of motivation, including attribution theory (Weiner et al., 1971), self-efficacy theory (Bandura, 1986), and classic expectancy/value theory (Atkinson, 1957); and, more recently, achievement goal theory (Dweck \& Leggett, 1988; Nicholls, 1984). Wigfield and Eccles (1992) pointed out that these theories often emphasize the role of expectancy more than values and argue that motivation associated with a specific content demands studies on values of specific learning tasks in the content.

In classroom research, motivated learning behavior is found to be directly associated with students' expectancy for success and perceived task values in knowledge domains and learning activities (Jacobs \& Eccles, 2000). Studies on learner motivation in mathematics (Eccles \& Wigfield, 1995) have shown, in exploratory and confirmatory factor analyses, three value dimensions: perceived importance (attainment value), intrinsic interest (intrinsic interest value), and perceived utility (utility value). Attainment value has been defined as personal importance of success in an activity, intrinsic interest value as the enjoyment from participating in an activity, and utility value as perceived usefulness of participating in an activity to life (Eccles \& Wigfield, 1995). Expectancy for success is defined as individuals' beliefs about how well they will do on upcoming activities. According to Eccles and Wigfield (1995), expectancy for success functions as an independent motivation dimension clearly separated from the task-value dimensions.

The last, but equally important dimension in the expectancy-value framework is cost, defined as perceived consequences derived from participating in an activity, such as perceived difficulties, fear of failure, lost opportunities from choosing one activity over another (Wigfield, 1994). For example, in research in mathematics 
(Eccles \& Wigfield, 1995) cost is operationalized and measured as task difficulties and required effort of a task. An important finding is that perceived difficulty alone may not be a major factor determining motivation (measured as effort); other sources of cost are suspected to be at work to hinder students' achievement motivation in the setting of learning mathematics (Eccles \& Wigfield, 1995; Wigfield \& Eccles, 1992).

Cost is apparently opposite to the other value dimensions: attainment, interest, and utility, which share positive characteristics. Although cost is labeled and categorized traditionally as a type of value, we believe that using "value" to describe the nature of this dimension may be misleading because of its role of countering the positive values. In addition, few studies have examined the relationship of cost with the other value dimensions. Thus, little evidence is available for determining whether it is independent from the other three task values. In the current study, cost was studied as a separate dimension in the construct. This and subsequent research studies (e.g., Jacobs, Lanza, Osgood, Eccles, \& Wigfield, 2002; Wigfield et al., 1997) have confirmed the clarity of the five-dimension expectancy-value framework and its motivational functions in academics and sports.

Expectancy beliefs and task values are content domain specific in that they are often perceived in terms of benefits and barriers in a content being learned. Achievement motivation relies on the extent to which the learner balances the expectancy belief for success, perceived task values, and cost. In different content domains, such as mathematics or sports, children and adolescents demonstrate drastically different expectancy for success and different appreciation for task values (Eccles \& Wigfield, 1995). A recent analysis of a 12-year longitudinal data on children/adolescents' expectancy values in different school subjects revealed that the decline of perceived physical competence and values of sports accelerates in a curvilinear pattern during adolescent years (Jacobs et al., 2002), which coincides with the sharpest decline of physical activity in both male and female adolescents (Caspersen, Pereira, \& Curran, 2000). It is believed that when learners become able to distinguish their competency or lack thereof in particular content domains, the learners are able to make choice decisions on whether to engage in the content. Perceived task values, on the other hand, may have a strong and long influence on learners' motivation on whether to continue the chosen content.

As children grow, becoming adolescents and then adults, their self-concept system about an activity changes and becomes steady with increasingly accurate conceptions of their competence and of the values and cost in the activity (Jacobs et al., 2002). The perceived competence of self and perceived values and cost of an activity often form a basis of motivation for adolescents and young adults (Eccles \& Wigfield, 1995). The dimensions in the expectancy-value framework have been examined in mathematics, reading, and sport domains. Jacobs et al.'s (2002) analysis of a growth model with 12-year longitudinal data has shown that the expectancy beliefs for success continued to decrease until late adolescence. The perception of the three values decreased during elementary school and early middle school years, but began and continued to increase during high school years in reading and sport domains. It is suggested (Jacobs et al., 2002) that when growing older, learners may rely more on perceived values of a learning activity than on expectancy beliefs for success to motivate themselves because they have accu- 
rate conceptions of competence and they choose carefully to invest their competence and effort in those activities and tasks they value.

\section{The Role of Cost}

The role of cost has been theorized to be crucial to the development of overall motivation. Although young children may not be able to differentiate cost associated with participation in a particular activity, adolescents and young adults are very clear about the trade-off between the values an activity provides and the cost it may demand (Jacobs \& Eccles, 2000). It can be assumed that perception of an imbalanced value-cost relationship may hinder motivation. Cost, as a dimension in the task-value framework, has rarely been studied in both classroom-based education and physical education. In the one study where cost was operationalized and measured as difficulties in math tasks and effort required to work on the difficult math tasks, Eccles and Wigfield (1995) found that perceived difficulty and effort were negatively correlated with the attainment, interest, and utility values with low-to-moderate strength ( $r$ ranged from -.13 to -.44$)$. The researchers concluded that when adolescents think a task is too difficult, they are likely to devalue it, which decreases their motivation for studying it. In a study on expectancy-value-based motivation in elementary school physical education (Xiang, McBride, Guan, \& Solmon, 2003), cost was simply excluded, but was recommended as a focus for future research. Owing to the fact that cost has been overlooked in research on expectancy-value motivation, we know little about what it is in physical education that constitutes cost and the role of cost in learner motivation in physical education. Without an understanding about the role of cost, findings about the motivation consequences of expectancy values in physical education may be compromised because the full extent of the mediation by perceived cost is not considered.

\section{Purpose of the Study}

In summary, the research evidence suggests that adolescents and young adults often base motivation on expectation for success and, more likely, on perceived values an activity offers. Perceived cost, which is defined as any sense of loss and suffering from participating in an activity, is assumed to be working against the expectancy-value-based motivation. The expectancy-value motivation theory postulates that motivation can only be achieved when perceived values override cost. Owing to limited research on cost, we know little about the role of cost, its sources, and its effect on motivation in physical education. Consequently, little is available for physical educators to act on in developing a motivating curriculum and helping students become and stay motivated by overcoming perceived cost.

This study was designed to explore types of perceived cost in college physical education and the extent to which the cost might affect motivation. The purpose of this study was to articulate perceived cost in relation to perceived values and motivation in required college physical education. A second purpose was to identify possible sources of cost that might hinder students' motivation. We were also interested in knowing whether perceived task values can override the impact of 
perceived cost on motivation or if the strength of perceived task values deteriorates as a result of the impact of cost (Jacobs et al., 2002).

To effectively study the sources of cost and its role, we believe, studies should be conducted in the educational environment where hypothesized cost is most likely to exist and be perceived. It is equally important that the data are collected from a student population mature enough to articulate the sources and roles of cost so that the results might be useful for future researchers as they formulate and articulate the structure of cost to motivation in physical education at various educational levels. For these reasons, we decided to conduct the study in Chinese universities where physical education is still a required course for all students. In addition, the centralized national curriculum and the teacher-controlled instruction might impose a learning environment in which most of the possible sources of cost can be perceived.

Studying Chinese students' motivation for physical education and physical activity has the potential to contribute to the effort of developing active lifestyles in Chinese adolescent and youth populations. Similar to the prevalence of child/ adolescent obesity in the United States, children and adolescents in China have become increasingly obese during the past 20 years. According to a recent report (Ji, Sun, \& Chen, 2004), the rate of overweight among Chinese children and adolescents has increased from $1 \%$ and $2 \%$ for boys and girls in 1985 to about $7 \%$ and $5 \%$ in 1995 , to about $25 \%$ and $17 \%$ in 2000 in major metropolitan areas. Helping students develop strong motivation for physical activity has become a central goal in physical education, and that battling current low motivation in physical education classes has become a central issue in curriculum reform.

\section{Methods}

\section{Research Design and Participants}

We used a mixed design. Both quantitative and qualitative data were collected from a sample of college students $(n=368$, mean age $=20.4, S D=1.34$, range $=$ 17-24) randomly selected from four universities in a major city of China. The universities were randomly selected from a pool of 24 universities in the city with stratification on government-designated academic ranking so that the student sample would represent those from different locales and different universities. The university sample included a National Key university, two Provincial Key universities, and a Regular university. These rankings represent the different academic reputations and the level of government funding, with the National Key being the most privileged and the Regular, the least. The ranking also determines where a university can recruit its students. Universities ranked as National Key can admit students from throughout the country; Provincial Key, a province; and those ranked Regular primarily admit local students who are not admitted by National Key or Provincial Key universities. In short, sampling students in this group of universities enhanced the representation of students in terms of their academic aptitudes, social and cultural background, and personal experiences.

Students were sampled from a pool of 403 cohort classes from the four universities. Each class consisted of about 30 students in physical education. Based on the limited available resources for the study, we arbitrarily decided to select 20 
classes to collect data from. Sampling was conducted using a random drawing system in which the researchers used the standard random table to select the classes first for the purpose of sampling efficiency. Within the selected classes, a sample of students ( $n$ ranging from 15 to 20) was randomly selected from all who volunteered for the study. College students were chosen because they (a) are able to differentiate their own self-beliefs, (b) have had extensive experience in physical education and physical activity, and (c) are able to logically elaborate their motivation decisions. Consent forms were received before data collection. The random sampling rendered more female students $(n=245,67 \%)$ than males $(n=$ $123,33 \%)$ and included 110 freshmen (30\%), 109 sophomores $(30 \%), 66$ juniors (18\%), and 83 seniors (22\%).

\section{The Research Setting and Physical Education Programs}

There are about 12,000 students in the universities. They were required to take physical education each year. An academic semester consists of 16 weeks. A variety of sports and physical activities was offered in the physical education programs that were based on the national curriculum. At the time of the study, students were studying tai chi, table tennis, badminton, soccer, basketball, volleyball, tennis, aerobics, orienteering, running (track), gymnastics, and theories associated with these activities. In addition to the activities, weight training, orienteering, and swimming were offered as specialty content to seniors during the period of the study. On each campus, the following facilities were available: at least a gymnasium that has a basketball court, a weight room, an outdoor track field, about six or more outdoor basketball courts, three or four volleyball courts, four tennis courts, and a table tennis house. Physical education classes were taught in a very structured manner, in which teachers followed predetermined lesson plans and organized student practices in required formations. The command teaching style was the primary teaching approach, and students were expected to follow teachers' directions in the entire lesson.

The curriculum was multiactivity based in that it was organized and sequenced based on individual sport and physical activity. Freshmen, sophomores, and juniors were not allowed to choose content. They were taught in cohort classes and followed a structured schedule to study two or three designated sports or physical activities. Seniors were allowed to make choices about what activities to study. In other words, they had some degree of autonomy in selecting activities they were interested in.

In addition to physical education, all students (who were required to live on campus in these universities) were required to participate in a 20-min calisthenics exercise every morning from 6:55 to 7:15. Students performed the calisthenics on their assigned locations and were required to be in the assigned squad formations. Cued by music and led by a student leader or a physical education teacher who was on duty for the week, students performed the calisthenics in unison. Attendance was taken and recorded by class/dorm leaders, and was reported to physical education teachers who were responsible for the class or dormitory.

The students were also required to participate in at least one after-class exercise of their choice each week. Each student was issued an exercise participation record card. Each time the student took part in an after-class exercise session, a 
checkmark was placed for that week. A student was expected to accumulate 16 checkmarks during a semester. At the end of a semester, all students were required to turn in their cards to their physical education teacher. The participation record was used as part of the physical education grade (for the affective-attitude category), which was officially recorded on students' final transcripts as part of their academic record.

The teaching force consisted of 74 full-time physical education specialists. These teachers were responsible for all aspects of the physical education programs. Ten of them had a master's degree, one was studying for her doctoral degree, and all others held a bachelor's degree in physical education. Each teacher had a load of teaching seven 100-min lessons per week. A few (about 18) were also responsible for coaching varsity teams with reduced teaching load (about two lessons per week).

\section{Variables and Instruments}

The expectancy beliefs and task values were measured using a 14-item Chinese version of Self- and Task-Perception Questionnaire (Eccles, Adler, \& Meece, 1984) originally developed for high school students in mathematics classes. The original instrument includes 19 items, 12 of which measure expectancy beliefs and perceived task values and the remaining 7 measure perceived difficulty and effort specific to studying high school advanced mathematics. Similar to the Xiang et al. (2003) study, we adapted the 12 expectancy belief and task value items (on a 5-point Likert-type scale) to physical education as displayed in Figure 1. Two open-ended questions were used to elicit the students' perception of possible cost to motivation and choice decision motivation in physical education.

Expectancy Beliefs. Expectancy beliefs were measured using five items. These items demonstrated high-quality psychometric properties in a series of studies (see Eccles \& Wigfield, 1995). We replaced the term mathematics with "physical education classes" and added the words this semester to help participants delimit a frame of reference for college physical education.

Perceived Task Values. The task values were measured using seven items. As in the original instrument, two items are used to measure each of the intrinsic interest and utility values and three items measure attainment value. Eccles and Wigfield (1995) demonstrated that the items can provide data with high validity and reliability. Modifications similar to the above were made to the items.

Cost and Choice Decisions. In the current study, cost was conceptualized and operationalized as possible causes to the loss of motivation for physical education. This operational conceptualization is different from that used in classroom studies in that we chose to leave defining components of cost open for the participants to determine instead of preoperationalizing it as consisting of perceived task difficulty and effort only (Eccles \& Wigfield, 1995). Thus, data on cost were gathered using an open-ended question: "If there is anything that would make you dislike physical education, what is it? Why?" Using the open-ended question allowed the researchers to establish a basic conception of cost as constructed by the students, because of the fact that no instrument was developed to measure this construct in 
Expectancy Beliefs $(\alpha=83)$

How well do you think you are doing in physical education? (very poorly $=1$, very well $=5$ )

Compare to others, how well do you expect to do in physical education? $($ much worse $=1$, much better $=5)$

How good at physical education are you? (not at all good $=$ 1 , very good $=5$ )

If you rank all students from the best (5) to the worse (1), where would you put yourself? (worst $=1$, best $=5$ )

How have you been doing in physical education this year? (very poorly $=1$, very well $=5$ )

Attainment Value $(\alpha=.63)$

Is the amount of effort it takes to do well in physical education worthwhile to you? (not at all $=1$, very much $=5$ )

To me, being good at physical education is important. (not at all true to $m e=1$, very true to $m e=5$ )

How important is it to you to be good at physical education? (not at all important $=1$, very important $=5$ )

\section{Intrinsic Interest Value $(\alpha=.86)$}

I find working on physical education activities are ... (very boring $=1$, very interesting $=5$ )

How much do you like taking part in physical education activities? (not at all $=1$, very much $=5$ )

$\underline{\text { Utility Value }}(\alpha=.81)$

How useful is learning in physical education for you? (not at all useful $=1$, very useful $=5$ )

How useful is what you have learned in physical education for your daily life after school hours? (not at all useful $=1$, very useful $=5$ )
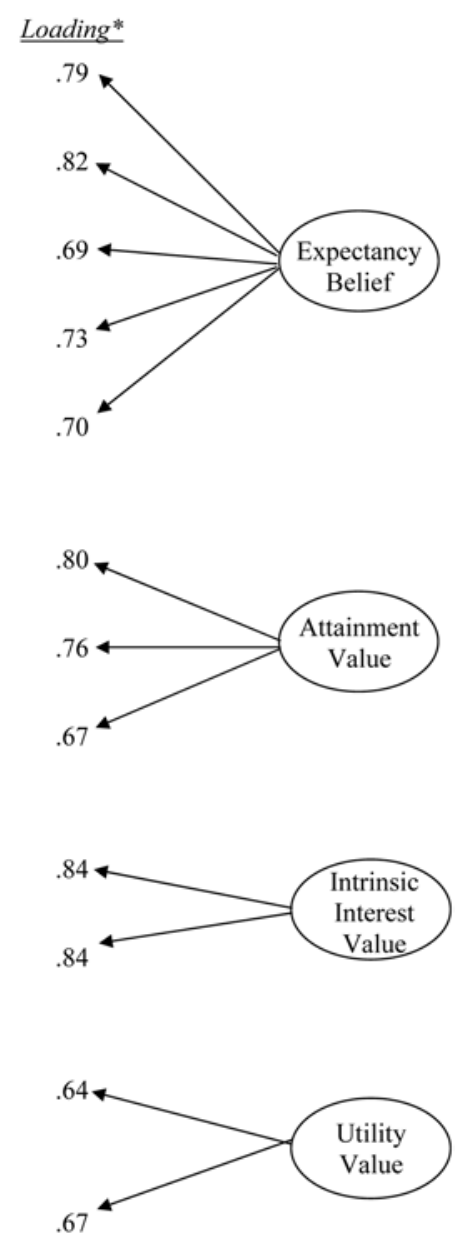

Figure 1 - Loadings from confirmatory factor analysis on the expectancy-value construct. *Standardized estimates from the confirmatory factor analysis.

physical education. Choice decisions were measured using another open-ended question: "If you have a choice whether to take physical education, would you rather not take it or you still want to take it? Why?" Follow-up interviews were conducted to further clarify their responses to both of these why questions.

Psychometric Property of the Measures. The questionnaire was translated into Chinese by the researchers, who are bilingual physical education scholars, and the translations were validated by a panel of bilingual scholars through comparing the consistency between the two language versions. A factor-analytical process using the confirmatory factor analysis procedure on the current data yielded acceptable construct validity, as reported in Figure 1. Results of the model-data fit tests were 
deemed satisfactory based on $\mathrm{Hu}$ and Bentler's (1999) recommendations: the standardized root mean square residual was .029 (threshold $\leq .09$ ) and root mean square error of approximation was .033 (threshold $\leq .06$ ). The computed Cronbach (1951) $\alpha$ coefficients indicated that all the measures demonstrated high reliability except that for the attainment dimension (see Figure 1). Because the $\alpha$ method is based on item covariance, it is considered the coefficient of precision reflecting the estimated probability of acquiring identical scores from respondents taking the same test multiple times and assuming no change in respondents (Crocker \& Algina, 2006). An $\alpha$ coefficient lower than its validated criterion determined in validation studies reflects a faded precision level caused by inconsistency or indecision in respondents when responding to the test items. In our study, the low $\alpha$ coefficient in attainment value might indicate a faded precision of participants in recognizing the importance of physical education.

Contextual Information of Instruction. Physical education classes $(n=20)$ from which the students were sampled were observed once a week for 8 to 12 weeks throughout a semester by the second author and trained graduate students. Observation for a class stopped when the researchers decided that subsequent observation would not provide new information about student learning experiences (data exhaustion achieved). A total of 186 lessons were observed. Field notes were taken to provide anecdotal information about the instructional context and students' collective behavior in class. Given the descriptive nature of the study, we did not direct attention to any specific students in the classes. Thus, the role of the field notes in the study was to provide supplemental information for triangulation with other forms of data.

\section{Data Collection and Analysis}

In data collection, the participants completed the questionnaire individually in physical education classes. They were instructed to respond to the questionnaire independently and by relying on their own experiences in college physical education. They were ensured that their responses would not be used for grading purposes and would not be forwarded to their instructors under any circumstances.

Written responses to the open-ended questions were followed with short interviews by the data collectors in order to probe on answers to the why question. Because students' responses ranged from class size to equipment to schedule to teacher personality, follow-up probing questions were posed mostly for further clarifications of the initial responses. Examples include, "what style of teaching do you think will help students feel better and want to participate?" (if the initial written response was that the teacher was too strict using a totalitarian style), or "how many balls (equipment) do you think adequate for a volleyball class?" (if the initial written answer was that there were too few balls for students in a volleyball unit.) The follow-up interviews were conducted by the second author and graduate assistants separately in the next lesson following the one from which the questionnaires were collected. The follow-up interviews were conducted individually and took place in a quiet place not too far from the class but with as little interference as possible.

All students $(n=359)$ were interviewed except nine who were excused medically from taking physical education for the rest of the semester. Interview notes 
were recorded in writing for analysis. During the data collection, the participants were informed of the purposes of the study and were asked to respond independently and rate each item based on their own feelings and experiences in college physical education.

Quantitative data were reduced by the expectancy belief and task value dimensions. Descriptive analyses were conducted to examine the data normality and distribution of cost attributions. Based on the qualitative analysis of the responses from the open-ended questions and follow-up interviews, coding rubrics were developed. The researchers individually reviewed the rubrics, sample-coded qualitative responses, and reached a consensus about its accuracy. The rubrics, as seen in Table 1, were used in coding all qualitative data for statistical analyses. Chi-square analyses were conducted to test the association between perception of cost (if there were reasons to dislike physical education) and choice decisions (taking physical education). Given the moderate correlation among the task values ( $r$ ranged from .27 to $.44, p<.01$ ), MANOVA was conducted to examine if students differed in expectancy beliefs and perceived task values in terms of their perceived cost in the physical education curriculum.

Participants' written responses, observation notes, and short interview data on cost were transcribed, translated into English by the lead author, and analyzed using the constant comparison approach, in which open, axial, and selective codings (Strauss, 1987) were performed to generate major themes. In the analysis, data were categorized and recategorized until identified categories were exhausted. Triangulations were routinely conducted to enhance the trustworthiness (validity) of the information based on which major themes consistent with the conception of cost were developed. Themes were developed according to salient evidence that emerged from the coding and categorizing processes. Recurring themes were given additional analytical attention and used to develop grounded theories. In the process of building grounded theories, negative cases were sought, analyzed, interpreted to further strengthen the trustworthiness of the results. Triangulation was conducted throughout the analysis by constantly examining consistency among quantitative data, written and interview data, and the anecdotal observation notes.

\section{Results}

\section{Types of Cost}

The final sample included 351 students as a result of missing data. Most participants $(n=287,82 \%)$ indicated that there was at least one reason in their classes that might make them dislike physical education. As reported in Table 2, follow-up chi-squire analyses on the distribution by years in college revealed no statistically significant differences. Results in Table 3, however, did show that more females than males cited reasons that might lead them to dislike physical education. The remainder of the sample $(n=64)$ indicated either that they could not find anything as cost or that they enjoyed "everything" in physical education. Constant comparison analysis on reasons for "disliking physical education" revealed four themes or sources of cost: a "PE-for-PE" curriculum, a learner-unfriendly context, irresponsible teachers, and decontextualized assessments. Figure 2 describes the 


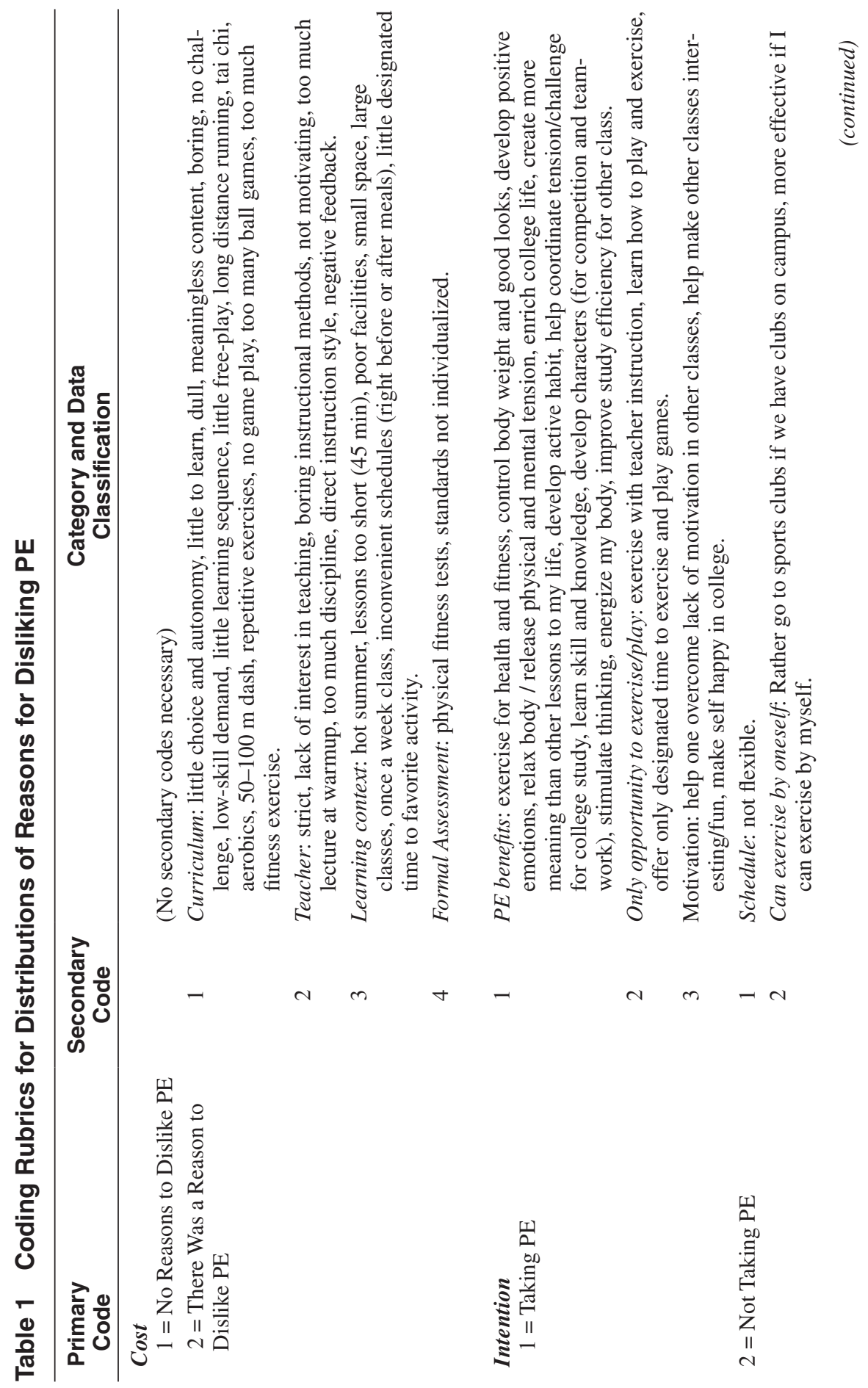




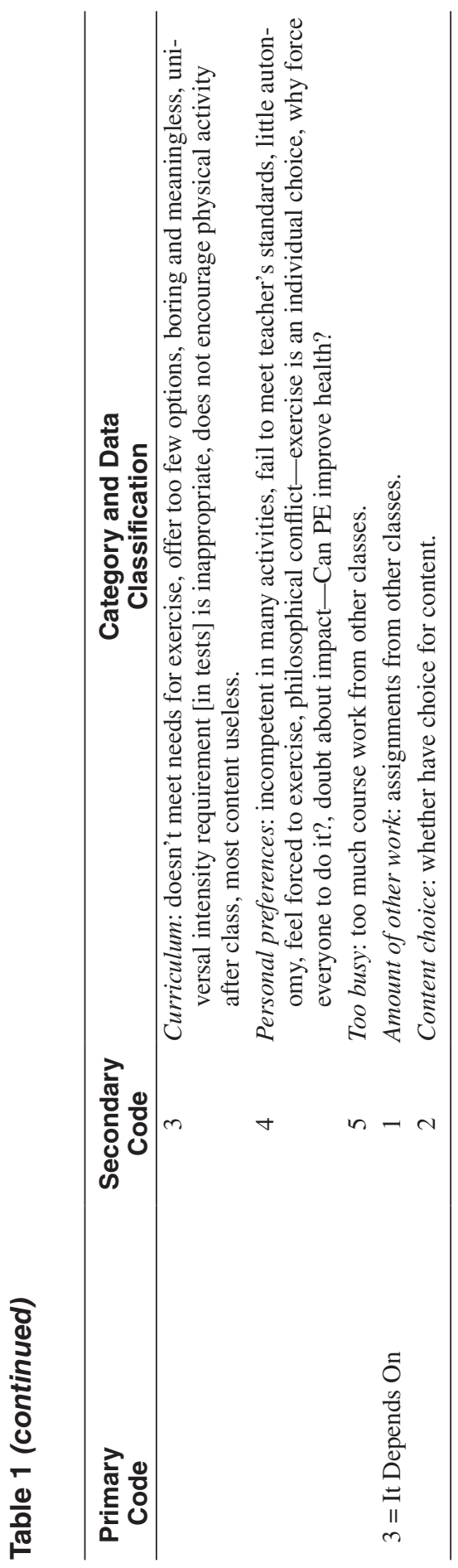


Table 2 Frequency Distributions on Disliking PE by Years in College $(N=351)$

\begin{tabular}{lccc}
\hline & \multicolumn{3}{c}{ Is There a Reason to Dislike PE? } \\
\cline { 2 - 4 } & No & Yes & Total \\
\hline Freshmen & 17 & 88 & 105 \\
Freq & 19.1 & 85.9 & 105.0 \\
Exp'd Freq & $16.2 \%$ & $83.8 \%$ & $100.0 \%$ \\
$\%$ & & & \\
Sophomore & 21 & 84 & 105 \\
Freq & 19.1 & 85.9 & 105.0 \\
Exp'd Freq & $20.0 \%$ & $80.0 \%$ & $100.0 \%$ \\
$\%$ & & & \\
Junior & 13 & 49 & 62 \\
Freq & 11.3 & 50.7 & 62.0 \\
Exp'd Freq & $21.0 \%$ & $79.0 \%$ & $100.0 \%$ \\
$\%$ & & & \\
Senior & 13 & 66 & 79 \\
Freq & 14.4 & 64.6 & 79.0 \\
Exp'd Freq & $16.5 \%$ & $83.5 \%$ & $100.0 \%$ \\
$\%$ & $\mathbf{6 4}$ & $\mathbf{2 8 7}$ & $\mathbf{3 5 1}$ \\
Total & $18.2 \%$ & $81.8 \%$ & $100.0 \%$ \\
& & &
\end{tabular}

Note. $\chi^{2}(1,3)=.99, p=.80$.

Table 3 Frequency Distributions on Disliking PE by Years in College $(N=351)$

\begin{tabular}{lccc}
\hline & \multicolumn{3}{c}{ Is There a Reason to Dislike PE? } \\
\cline { 2 - 4 } & No & Yes & Total \\
\hline Male & & & \\
Freq & 28 & 87 & 115 \\
Exp'd Freq & 21.0 & 94.0 & 115.0 \\
$\%$ & $24.3 \%$ & $75.7 \%$ & $100.0 \%$ \\
Female & & & \\
Freq & 36 & 200 & 236 \\
Exp'd Freq & 42.4 & 193.0 & 236.0 \\
$\%$ & $15.3 \%$ & $84.7 \%$ & $100.0 \%$ \\
Total & 64 & 287 & 351 \\
& $18.2 \%$ & $81.8 \%$ & $100.0 \%$ \\
\hline
\end{tabular}

Note. $\chi^{2}(1,1)=4.289, p=.038$. 
distribution of the perceived cost according to the ratio between the number of students identifying reasons for each of the categories and the total number of students $(n=287)$.

“PE Is for PE, Not for Us.” About $45 \%$ students referred their negative view of physical education to the curriculum. The universities used a centralized curriculum in which most content was predetermined. Flexibility to deviate from the curriculum was limited. Most content or even tasks in the curriculum were nonnegotiable. This created a mismatch between activities taught and student interests. As a student observed,

The teacher makes PE is for PE [the content], not for us [the students]. This is no fun! They lack skills to motivate students and they do not care about helping [us] develop interests in physical activities. All tasks are for covering the curriculum, this is meaningless to me.

For example, tai chi, a Chinese traditional activity, was a required content for each semester. Many students felt that requiring everyone to learn tai chi was demotivating. Some considered it useless to their lives, and others thought it dull and boring, not "developmentally appropriate" for them. Many thought it benefited only the elderly. Associated with the content-student mismatch was the feeling of lack of autonomy in learning. A student complained, "Too much discipline is involved in class. Physical education should be relaxing; students should feel free to make choices. Too much discipline destroys my motivation." Another student said, "One cannot play a sport well no matter how much one practices, if he/ she is not interested in it. Students should be allowed to choose [content] based on their interests." In addition, 144 students expressed a strong objection to fitness development activities, especially running, and thought they were boring and

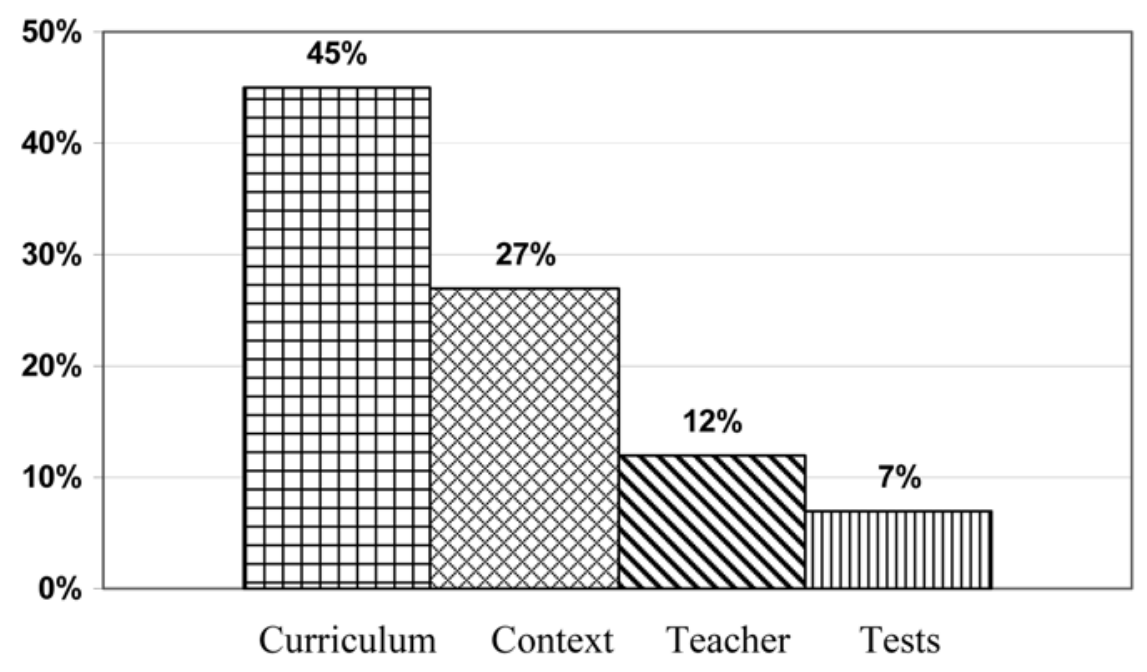

Figure 2 - Distribution of cited reasons for disliking physical education $(n=287)$. *Percentage: Number of students citing the reason divided by the total students responded. 
demotivating: "Running everyday seems a waste of time. We can spend this time to learn other activities."

“A Learner-Unfriendly Context." Many (27\%) did not think their learning contexts were motivating and conducive to learning. Because of limited indoor facilities, most physical education lessons were taught outside; thus, weather became a concern. Classes were large ( 30 students). Students complained that there was not enough equipment or facilities to use: "There are too many people in my badminton class. We have to share courts and shuttlecocks. So there is no continuation in drills and games. This makes a pretty exciting activity boring." Observation indicated that four courts were set up in an indoor basketball gymnasium for the badminton unit; usually six to eight students shared a court. Both the teacher and students agreed that it was "too crowded" to either receive health benefits or learn skills.

Disappointment with the physical context apparently is associated with goal conflict between students who thought physical education ought to develop their skills for sport competition and those who simply wanted to exercise for health. Some students, especially males, expressed that insufficient facilities and large classes demotivated them because "I have to play with low-skilled students. I can't put forth my full effort." Others complained, "This (poor facilities, crowded classes) makes instruction ineffective. There is too much off-task time waiting to do something, so exercise intensity is too low." Unlike their teachers who considered it difficult to change the context without an overall facility renovation, the students thought the problem could be easily resolved if they were allowed to choose the content to be learned and classes to be in.

"Irresponsible teachers" and decontextualized assessments are two additional costs. About $12 \%$ of students thought their teachers were more concerned with "getting the content covered" than "teaching us something." Teachers were usually perceived as being "too strict" with disciplinary measures and not concerned with students' learning. A teacher was described by several students as being "irresponsible, with low energy, expressionless in instruction, and lazy." A small percentage of students (7\%) were critical about the assessment and grading system. They realized that the norm-referenced assessment was inappropriate and demotivating. As one student put it, "It is not right to assess all students with one standard, people are different. Tests and grading should take into account individual differences and focus on learning and improvement." A total of 20 students identified physical skill tests as a contributor to their possible disliking of physical education: "[The testing] makes going to classes is for the tests. The achievement doesn't reflect our effort." These assessments made students look at the content in a different light, and one student commented:

I like physical education, but these tests make interesting content a heavy burden for me. Instead of enjoying the activities, I have to think about how to make the grade all the time in class, which is not motivating at all.

Another student echoed, "Tests and making the credits create a pressure for most of us. They make PE another area of study, which is not enjoyable and hurts my interest in physical education." 


\section{Motivation by Choice Decisions}

Despite the perceived cost, most students $(n=326,92 \%)$ indicated that they would take physical education even they could choose not to. Figure 3 shows the distribution of the three primary reasons for their choice decisions. The primary reasons for the decision include (a) health benefits $(n=228,64 \%)$; "physical education teaches how to exercise and skills for safe exercise, develops me as a holistic individual, and enhances my fitness for health"; (b) physical education was the only opportunity to exercise during busy college life $(n=116,33 \%)$, a student summarized:

We have a busy college life with so much course work. Physical education is the only time for me to exercise. I am already lazy. Without physical education, I would be even worse and won't be able to change it [laziness].

and (c) physical education gave broader motivation for other aspects of college life, especially for learning in other subject matter $(n=54,15 \%)$ : "Physical education can boost our energy for daily life, which is important for my work and study. It helps release mental tension, stimulate thinking, and energize my body, which increases my motivation to learn in the classroom." Many students cited more than one reason. Few students cited any particular physical activity or sports to be the primary reason for continuing physical education, but 249 stated that they would enjoy physical education a little better if they were allowed to make choices based on personal interests.

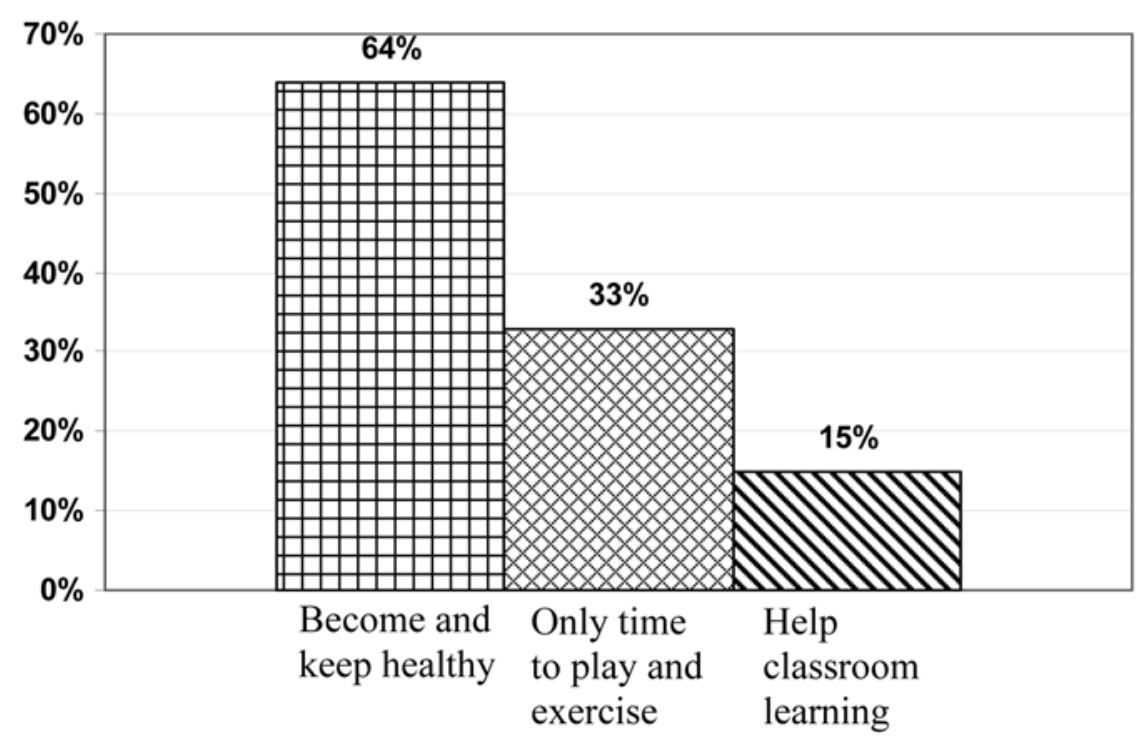

Figure 3 - Distribution of primary reasons for continuing physical education $(n=326)$. *Percentage: Number of students citing the reason divided by the total students responded. 


\section{Cost, Choice Decision, and Task Values}

A chi-square analysis was performed to examine the association between perception of cost (reasons for disliking physical education) and choice decisions (taking physical education). The result in Table 4 revealed no significant association: $90 \%$ of the 287 students $(n=257)$ who identified at least one reason leading to disliking physical education still wanted to take physical education, and $95 \%$ of the 64 students $(n=61)$ who did not identify any cost, made the same choice $\left(\chi^{2}=2.04\right.$, $p=.15)$.

To determine how students differed in task values based on their perceived cost, we divided students into two groups based on whether they considered the curriculum a cost because (a) the curriculum is the center of physical education experience, (b) it is the most cited cost in the data affecting students' motivation, and (c) the grouping provided relatively balanced groups for analysis. The MANOVA multivariate analysis showed that there was a statistically significant difference between the two groups (Hotelling's $T=.30, F_{4,346}=2.76, p=.03, \eta^{2}=$ .03 , estimated power $=.76$ ). As can be seen in Table 5 and 6 , the follow-up MANOVA univariate analysis revealed that students who cited the curriculum as motivation cost rated intrinsic interest lower $(M=3.67, S D=.80)$ than those who did not $\left(M=3.92, S D=.79 ; F_{1,349}=8.46, p=.004, \eta^{2}=.24\right.$, estimated power $=$ $.83)$. No statistically significant differences were found in attainment and utility values between the groups.

\section{Discussion}

Cost has long been considered a critical component that influences learner motivation by mediating positive perception of task values in content (Jacobs \& Eccles, 2000). The qualitative data from the students suggest four possible sources of cost among which the curriculum and learning context were reported by a significant number of students to be the most detrimental to their motivation. For them, the cost distanced and alienated them from the content and learning.

Table 4 Frequency Distributions on Choosing PE by Reason $(N=351)$

\begin{tabular}{lccc}
\hline & \multicolumn{2}{c}{ Choose PE? } & \\
\cline { 2 - 3 } Reasons to Dislike PE? & No & Yes & Total \\
\hline No & 3 & & \\
Freq & 6.0 & 61 & 64 \\
Exp'd Freq & $4.7 \%$ & 58.0 & 64.0 \\
$\%$ & & $95.3 \%$ & $100.0 \%$ \\
Yes & 30 & & \\
Freq & 27.0 & 257 & 287 \\
Exp'd Freq & $10.5 \%$ & 260.0 & 287.0 \\
$\%$ & & $89.5 \%$ & $100.0 \%$ \\
\hline
\end{tabular}

Note. $\chi^{2}(1,1)=2.042, p=.153$. 
Table 5 Means and Standard Deviations on Expectancy and Values Between Perceptions of Curriculum as Cost Groups $(N=351)$

\begin{tabular}{lcc}
\hline & $\begin{array}{c}\text { Curriculum a Cost } \\
(\boldsymbol{n}=\mathbf{1 5 7}) \\
\text { Mean / SD }\end{array}$ & $\begin{array}{c}\text { Curriculum Not A Cost } \\
(\boldsymbol{n}=\mathbf{1 9 4}) \\
\text { Mean / SD }\end{array}$ \\
\hline Expectancy & $3.33 / .59$ & $3.42 / 1.02$ \\
Attainment & $4.24 / .77$ & $4.26 / .71$ \\
Interest & $3.67 / .80$ & $3.92 / .79$ \\
Utility & $3.81 / .83$ & $3.89 / .81$ \\
\hline
\end{tabular}

Table 6 MANOVA Univariate Test Results Between Perceptions of Curriculum as Cost Groups

\begin{tabular}{lccccc}
\hline Variable & Type III SS & df & MS & $\boldsymbol{F}$ & $\boldsymbol{p}$ \\
\hline Expectancy & .758 & 1 & .758 & 1.035 & .310 \\
Attainment & .015 & 1 & .015 & .027 & .869 \\
Interest & 5.343 & 1 & 5.343 & 8.461 & .004 \\
Utility & .681 & 1 & .681 & 1.014 & .315 \\
\hline
\end{tabular}

We think the data has ramifications beyond the setting. We believe that the issue of curriculum alienation may be observed in many physical education programs in many countries. Physical education is often focused on teaching the mechanics of physical movement for students to become proficient in performing the physical movement, or engaging students in active exercise regimens to receive health benefits. The teaching approach is usually rigid and inflexible. Teachers often emphasize class discipline, organization, and order over learning. Our data seem to suggest that students often do not understand the reasons why they should learn in these ways. Implicitly, the students criticized the teachers for treating the content superficially and failing to use appropriate approaches to engaging students in meaningful learning. For example, the students' resistance to learning (or doing) tai chi every semester appears to declare that they did not see any relevance in the movement anymore, nor did the students who were asked to play sports with low-skilled peers in classes.

Superficial teaching is not alone in physical education. In reading, for example, researchers (Beck \& McKeown, 2001) found that teaching the mechanics of reading or for understanding obvious ideas in the text leads to students' resistance. In this environment, students become used to processing information at surface level and become resistant to challenging work. Beck and McKeown (2001) further illustrated that when a reading curriculum was changed from simply studying mechanics and texts to providing choices for a deep understanding (e.g., using the Question the Author approach), students became much more motivated and engaged, and changed their views about reading.

An important finding lies in what did not appear in the data. Few students cited physical discomfort, low skills, or negative social-interactive reasons to be 
cost to their motivation. These factors are associated, though loosely, with constructs of effort, perception of ability, and social evaluation. Research literature has suggested that negative responses in these constructs are detrimental to motivation (Wigfield, 1994). The educational system in China constantly emphasizes effort over ability, but publicizes performance records for all learners at all school levels in an attempt to link effort to performance, and to social recognition. The impact of such a learning environment on students' motivation in various subjects has been reported recently in a study in Korea (Bong, 2004). It is likely that by the time entering college, students in these educational environments have become so accustomed to exerting maximal effort and accepting social evaluations, including negative ones, that they are no longer sensitive or responsive to the negative impact of these experiences on motivation.

Our above reasoning seems to suggest a positive outcome from negative learning experiences. We welcome the fact that physical discomfort, low skills, and negative social evaluations might not cost students' motivation in physical education. Theoretically, our reasoning suggests a need to further clarify educational meaning and value of these potential cost. On the one hand, these potential costs, especially negative social evaluations, may lead to the syndrome of "learned helplessness" (Martinek \& Griffith, 1994). On the other hand, a "feeling good curriculum" (Stout, 2000) without truthful feedback and evaluation would ill prepare students in pursuit of the learning goal.

It is interesting to notice in the MANOVA results that students who cited cost did not differ in attainment and utility values of physical education, but the two groups did differ in the value of intrinsic interest. Those who cited the curriculum as a cost considered physical education less interesting. They expressed frustration on lack of curricular opportunity for them to choose the content they were interested in. Coupled with the themes pointing to other sources of perceived cost, context, teacher/teaching styles, and assessment, the data from the study clearly suggest that lack of autonomy is a salient, overarching theme that cuts across all identified cost categories. The finding suggests that "PE for PE's sake" does not give students a sense of ownership about the content and the goal of learning. At the college level, it does not take much time for students to realize the extent of autonomy or lack of it in physical education.

Student autonomy and ownership relies on an understanding of values in the content. The more explicitly the values of an assignment are explained, the more likely students will become engaged in the assignment and remain motivated to further their study in the content area (Paris, Lipson, \& Wixsom, 1994; Wigfield, 2000). There are few reports about the impact of cost on task values and about whether the task values are resistant or immune to the impact of cost. Our data seem to indicate that task values did override the impact of cost on motivation. Although students citing the cost were likely to state their motivation was affected, they were still motivated enough to continue to choose physical education. Our data further revealed that attainment and utility were two dominant values the students held strongly for physical education. They believed that physical education provided opportunities to exercise for health and motivate them to meet challenges in college life. This belief appears to be unaffected by perception of the 
curriculum-related cost, suggesting a possibility that the cost is likely to be overridden by emphasizing positive values in the content.

Giving students' choice seems to be an effective approach to motivation. Horner and Shwery (2002) suggest that teachers should invite students to develop their problems to solve in reading as a primary motivation strategy. Prusak and Darst (2002) reported that providing choice in physical education facilitated adolescent girls' motivation to engage in physical education. These curriculum-centered motivation strategies seem to directly result in improved learning, instead of mere change of students' motivation dispositions (Burke, 1995). The students in our study seemed to demand curricular opportunities that allow them to make choice decisions about what to learn. Their voices demand a constructivist curriculum approach in this and any similar educational settings. As having been widely elaborated in the literature, a constructivist physical education curriculum focuses on providing multiple opportunities to participate in learning important concepts involved in physical activity, surpassing merely providing superficial information and mechanism of physical skills and sports. These constructive opportunities should be essential and readily available for physical education students at the college level. In physical education research, additional studies are needed to further investigate the impact of choice on student motivation and learning outcomes.

In summary, this study has revealed several important sources of cost to college students' motivation in physical education. The most salient source of cost seems to be the curriculum itself. Although the impact of cost on students' choice decisions was not found detrimental, students who perceived a curricular-related cost did rate their interest in physical education lower than those who did not perceive any cost. Perception of cost did not seem to impact choice decisions to take physical education in the future. However, this finding alone may not be strong evidence suggesting a high motivation. At the college level, most students may have developed a stable value system that may not be fully developed in younger learners.

Two limitations should be considered in understanding of the findings in this study. First, although we see similar or comparative circumstances in physical education across cultural boundaries, caution must be taken when applying the findings outside the Chinese higher education system. Second, our conceptualization of cost components and the interpretation of them were grounded in the data gathered from using the open-ended questions about cost. Our choice of using this data-driven approach to conceptualizing cost is different from using a theorydriven approach that would lead to an exploration of the role of task difficulty and effort as potential cost components. Although the data did not point to either task difficulty or effort as cost, the results should not be taken as though task difficulty and effort should not be understood as cost components in physical education.

\section{Acknowledgments}

We thank the Department of Physical Education of Southeast University of China for providing course release time for Xinlan Liu and graduate assistants for this study. 


\section{References}

Adam, T.M., \& Brynteson, P. (1992). A comparison of attitudes and exercise habits of alumni from colleges with varying degrees of physical education activity programs. Research Quarterly for Exercise and Sport, 63, 148-152.

Atkinson, J.W. (1957). Motivational determinants of risk taking behavior. Psychological Review, 64, 359-372.

Bandura, A. (1986). Social foundations of thought and action: A social cognitive theory. Englewoods Cliffs, NJ: Prentice-Hall.

Beck, I.L., \& McKeown, M.G. (2001). Inviting students into the pursuit of meaning. Educational Psychology Review, 13, 225-241.

Bong, M. (2005). Within-grade changes in Korean girls' motivation and perceptions of the learning environment across domains and achievement levels. Journal of Educational Psychology, 97, 656-672.

Burke, D.J. (1995). Connecting content and motivation: Education's missing link. Peabody Journal of Education, 70, 66-81.

Caspersen, C.J., Pereira, M.A., \& Curran, K.M. (2000). Changes in physical activity patterns in the United States, by sex and cross-sectional age. Medicine and Science in Sports and Exercise, 32, 1601-1609.

Crocker, L., \& Algina, J. (2006). Introduction to classical and modern test theory. Mason, OH: Thomas Wadsworth.

Cronbach, L.J. (1951). Coefficient alpha and the internal structure of tests. Psychometrika, 16, 297-334.

Dweck, C.S., \& Leggett, E.L. (1988). A social-cognitive approach to motivation and personality. Psychological Review, 95, 256-273.

Eccles, J.S., \& Wigfield, A. (1995). In the mind of the actor: The structure of adolescents' achievement task values and expectancy-related beliefs. Personality and Social Psychology Bulletin, 21, 215-225.

Eccles, J.S., Adler, T.F., \& Meece, J.L. (1984). Sex differences in achievement: A test of alternative theories. Journal of Personality and Social Psychology, 46, 26-43.

Fornia, D.L. (1959). Coeducational physical education in institutions of high learning. Research Quarterly, 30, 423-429.

Hensley, L.D. (2000). Current status of basic instruction programs in physical education at American colleges and universities. Journal of Physical Education, Recreation, and Dance, 71(9), 30-36.

Horner, S.L., \& Shwery, C.S. (2002). Becoming an engaged, self-regulated reader. Theory Into Practice, 41, 102-109.

Hu, L., \& Bentler, P.M. (1999). Cutoff criteria for fit indexes in covariance structure analysis: Conventional criteria versus new alternatives. Structural Equation Modeling, 6, $1-55$.

Jacobs, J.E., \& Eccles, J.S. (2000). Parents, task values, and real-life achievement-related choices. In C. Sansone \& J.M. Harackiewicz (Eds.), Intrinsic and extrinsic motivation: The search for optimal motivation and performance (pp. 408-443). San Diego, CA: Academic Press.

Jacobs, J.E., Lanza, S., Osgood, E.W., Eccles, J.S., \& Wigfield, A. (2002). Changes in children's self-competence and values: Gender and domain differences across grades one through twelve. Child Development, 73, 509-527.

Ji, C.Y., Sun, J.L., \& Chen, T.J. (2004). Dynamic analysis on the prevalence of obesity and overweight school-age children and adolescents in recent 15 years in China. Chinese Journal of Endemiology, 25(2), 103-108.

Keating, X.D., Guan, J., Piñero, J.C., \& Bridges, D.M. (2005). A meta-analysis of college students' physical Activity behaviors. Journal of American College Health, 54, $116-125$. 
Martinek, T.J., \& Griffith, J.B. (1994). Learned helplessness in physical education: A developmental study of causal attributions and task persistence. Journal of Teaching in Physical Education, 13, 108-122.

Nicholls, J.G. (1984). Achievement motivation: Conceptions of ability, subjective experiences, task choice, and performance. Psychological Review, 91, 328-346.

Paris, S.G., Lipson, M.Y., \& Wixsom, K.K. (1994). Becoming a strategic reader. In R.B. Ruddell, M.R. Ruddell, \& H. Singer (Eds.), Theoretical models and processes of reading (4th ed., pp. 788-810). Newark, DE: International Research Association.

Prusak, K.A., \& Darst, P.W. (2002). Effects of types of walking activities on actual choices by adolescent female physical education students. Journal of Teaching in Physical Education, 21, 230-241.

Stout, M. (2000). The feel-good curriculum: The dumbing down of America's kids in the name of self-esteem. Cambridge, MA: Perseus Books.

Strauss, A.L. (1987). Qualitative analysis for social scientists. New York, NY: Cambridge.

Trimble, R.T., \& Hensley, L.D. (1984). The general instruction program in physical education at four-year colleges and universities: 1982. Journal of Physical Education, Recreation, and Dance, 55(5), 82-89.

Trimble, R.T., \& Hensley, L.D. (1990). Basic instruction programs at four-year colleges and universities. Journal of Physical Education, Recreation, and Dance, 61(6), 64-73.

Weiner, B., Frieze, I., Kukla, A., Reed, L., Rest, S., \& Rosenbaum, R.M. (1971). Perceiving the causes of success and failure. Morristown, NJ: General Learning Press.

Wigfield, A. (1994). Expectancy-value theory of achievement motivation: A developmental perspective. Educational Psychology Review, 6, 49-78.

Wigfield, A. (2000). Facilitating children's reading motivation. In L. Baker, M.J. Dreher, \& J.T. Guthrie (Eds.), Engaging young readers: Promoting achievement and motivation (pp. 140-158). New York: Guilford.

Wigfield, A., \& Eccles, J.S. (1992). The development of achievement task values: A theoretical analysis. Developmental Review, 12, 265-310.

Wigfield, A., Eccles, J.S., Yoon, K.S., Harold, R.D., Arbreton, A.J.A., \& Blumenfeld, P.C. (1997). Changed in children's competence beliefs and subjective task values across the elementary school years: A three-year study. Journal of Educational Psychology, 89, 451-469.

Xiang, P., McBride, R.E., Guan, J., \& Solmon, M. (2003). Children's motivation in elementary physical education: An expectancy-value model of achievement choice. Research Quarterly for Exercise and Sport, 74, 25-35. 